\title{
Evaluation of Swallowing in Infants with Congenital Heart diseases
}

\section{By}

\author{
Maii Saad $^{1}$, Omayma Afsah ${ }^{1}$, Hemmat Baz ${ }^{1}$, Mohammed Ezz El-regal ${ }^{2}$, Tamer Abou-Elsaad ${ }^{1}$ \\ 1. Phoniatric Unit, ORL Department, Faculty of Medicine, Mansoura University, Egypt. \\ 2. Pediatric Gastroenterology Department, Faculty of Medicine, Mansoura University, Egypt.
}

DOI : 10.21608/mimu. 2021.69525.1013

Submit Date: $2021-03-26$

Accept Date : 2021-04-06

Available online:

\begin{abstract}
Background: Infants with congenital anomalies are at increased risk of developing oropharyngeal dysphagia. The life expectancy of pediatric patients with congenital heart disease has increased, and some studies reported the prevalence of dysphagia in this population. Objective: This pilot study aimed to describe the swallowing abnormalities found in infants with congenital heart diseases using clinical feeding evaluation (CFE) and videofluoroscopic swallowing study (VFSS). Methods: This study was conducted on 20 infants with congenital heart diseases in the age range 2-19 months (median seven months) with suspected aspiration and/or feeding problems. All cases were subjected to both clinical and videofluoroscopic evaluation of swallowing. Results and conclusion: The most commonly observed clinical finding was gagging during feeding in $85 \%$, cough during feeding in $65 \%$, and gurgly voice in $50 \%$ of infants. The majority of the studied infants $(75 \%)$ showed laryngotracheal aspiration caused by suck-swallow-breathing incoordination. Early diagnosis and management of dysphagia in this population are mandatory to prevent serious complications.
\end{abstract}

\section{Keywords}

- Infant

- Congenital

- Heart

- Aspiration

- Clinical

- Videofluoroscopic

- Dysphagia 


\section{INTRODUCTION}

Congenital heart disease (CHD) is defined as "a malformation of the heart or blood vessels that develops during the fetal period"(1). The prevalence is 9:1,000 live births, corresponding to 1.35 million newborns per year (2). It is classified clinically as cyanotic or acyanotic based on the gradient of oxygen saturation in the blood (3). Dysphagia (or swallowing disorder) refers to the difficulty in passing the bolus from the oral cavity to the stomach, making it difficult or impossible to secure the food intake. The swallowing disorders usually exist in cases of multiple diagnoses, syndromes, and associated comorbidities, which influence the overall development of children (4).

The life expectancy of patients with CHD has increased due to advances in early diagnosis (1), postnatal care, and surgical interventions (5). However, with higher survival rates, new challenges arose in these children's growth and development (6). Swallowing is a complex process that encompasses neurologic and aerodigestive coordination (7). Neurobehavioral markers, such as postural control and maturation of the suck- swallow- breathe coordination, are essential prerequisites for the child to progress toward oral feeding (8). The inability to feed often leads to an imbalance in energy intake, resulting in impaired growth (9). Due to compromised cardiopulmonary function, infants with CHD may need a longer time to feed or may present with poor appetite and food refusal (10). Signs of dysphagia in infants and young children include sucking and swallowing incoordination, gagging, vomiting, nasal regurge, excessive drooling, difficulty chewing, poor labial seal resulting in food falling from the mouth, oral residue, frequent coughing or choking, watery eyes, and a gurgly voice $(11,12)$. Dysphagia can induce feeding-related stress and challenges, affecting the psychosocial health of the child, family, and caregivers (13). Dysphagia impacts the quality of life of a child as the disorder may lead to malnutrition, dehydration, and aspiration pneumonia $(14,15)$.

The clinical feeding evaluation (CFE) is essential for determining symptoms and signs of dysphagia. It allows the clinician to make a preliminary determination of dysphagia diagnosis and the contributing cause and decide whether or not the condition necessitates additional instrumental assessment (16). Videofluoroscopic swallowing study (VFSS) has been shown to be a reliable technique in assessing the pediatric swallow and the aspiration risk. This allows modification of feeding techniques and prevents secondary complications (17). A few published studies and surveys measure the incidence and prevalence of dysphagia in pediatric patients with CHD. This study aimed to describe the swallowing abnormalities found in infants with congenital heart diseases (CHD) using clinical feeding evaluation (CFE) and videofluoroscopic swallowing study (VFSS).

\section{Subjects and Methods}

\section{Subjects:}

This pilot study was conducted on a sample of 20 infants younger than two years, who were presented to the Phoniatric Outpatient Clinic in Mansoura University Hospital. The studied infants were referred from Mansoura University Pediatric Hospital (MUPH) for suspected feeding and/or swallowing problems. Infants with CHD with suspected aspiration and/or feeding problems (e.g., coughing, or vomiting, failure to thrive, respiratory distress, apnea, asthma, cleft palate, bradycardia,..etc.) were included in the study. The study design employed was descriptive crosssectional with analytic component. Estimated timetable for the study was two years. 


\section{Exclusion criteria:}

- Infants who were lethargic and/or medically unstable and were generally unable to participate adequately in a VFSS.

\section{Methods:}

Every case was subjected to the following protocol of assessment (18):

I- Elementary Diagnostic Procedures: (bed-side evaluation)

A- Parent's Interview: Including the personal data of the infant, complaint, prenatal, perinatal, postnatal history, and detailed present history with an emphasis on the infant's feeding routine.

B- Oral-Motor and Feeding Assessment:

1. Pre-feeding assessment: Including parent-infant interactions, the presence or absence of head control and sitting balance, and the respiratory patterns.

2. Oral-Motor Structure and Function Assessment: Each structure was evaluated for precision, strength, range of motion, and symmetry of movement. Adequacy of function specific to the feeding and swallowing process was assessed.

\section{Feeding assessment:}

Observation of a trial of feeding was done to define normal and abnormal patterns of feeding domains, observe the infant/caregiver interaction, and define special adaptive equipments or positioning needs. Every effort was made to recreate the typical feeding experience for that infant. To that end, the infant was fed by his/her caregiver in their preferred feeding position using the infant's own foods and feeding utensils. Milk was used for evaluation. Feeding performance was assessed by "The Pediatric Feeding Assessment checklist" developed at Unit of Phoniatrics, Mansoura University Hospital (18), and items related to bottle-feeding was added. Behaviors in each domain were rated as normal and abnormal.

II- Clinical Diagnostic Aids:

(A) Videofluoroscopic evaluation of swallowing (VFSS): Videofluoroscopy was performed in the Fluoroscopic Unit, Radiology Department, Mansoura University Hospitals, equipped with a monitor system. The radiographic images of the VFSS were video recorded. Videofluoroscopic swallow observations and measures were done using the Pediatric Modified Barium Swallow Checklist that was applied in Phoniatric Unit, Mansoura University Hospitals, with the addition of comment on bottle feeding (18).

In infants who are fed only milk, VFSS was performed with bottle-feeding by mixing barium sulfate with the milk. If the infant was unable to suck, a $5 \mathrm{ml}$ syringe (without the needle) was used instead. None of the infants were receiving weaning food.

Two or three presentations of each food and/or milk consistency were given to obtain multiple trials of each texture. Newman et al., 2001 (19) stated that most infants do not demonstrate abnormalities in the first few swallows but display deterioration in swallowing function as they continue to feed. Each infant was fed by his or her typical caregiver or by the examiner. The feeding protocol began by presenting the infants with the bottle and nipple. If no aspiration occurred on the initial swallows, then the infant was allowed to suck on the bottle until there was a change in swallowing function, $60 \mathrm{ml}$ was finished, or the infant refused to suck. Overall, maximum radiation exposure was kept to a limit of 1 to 2 minutes which was within the safety margin (20). VFSS was analyzed to determine any 
problem in the oral and pharyngeal phase of swallowing.

\section{Ethical consideration:}

-The study was approved by the Institutional Research Board (IRB) of Mansoura faculty of medicine (MD/17.04.73).

-Informed verbal consent was taken from the parents of participating infants after assuring confidentiality.

-Confidentiality and personal privacy was respected at all levels of the study. Data was not used for any other purpose.

\section{Statistical analysis:}

Collected data were coded, processed, and analyzed using SPSS program version 17 windows to obtain qualitative data and Chi-Square test to compare two groups.

\section{Results:}

a- Demographic, cardiac and descriptive characteristics of patients are shown in table (1). Out of the 20 infants in the sample, 15 (75\%) were boys. The median age was seven months (minimum 2, maximum 19). Twelve infants had acyanotic CHD, and eight had cyanotic CHD. The studied infants scored I-II on the Modified Ross Heart Failure Classification for Children. Five infants had CHD without other comorbidity and fifteen infants had comorbidities, as reported by the pediatrician in the infant's medical report. Comorbidities included neurological (cerebral palsy and neurodevelopmental delay), genetic (Down syndrome), and GIT diseases (gastroesophageal reflux disease and esonophilic esophgitis).

Table (1): Demographic and cardiac characteristics of patients

\begin{tabular}{|l|c|c|}
\hline & \multicolumn{2}{|c|}{$\begin{array}{c}\text { Total } \\
(\mathbf{n = 2 0})\end{array}$} \\
\hline Age & \multicolumn{2}{|c|}{ Median 7 months (minimum 2, maximum 19). } \\
\hline Sex & \multicolumn{2}{|c|}{$\%$} \\
\hline Male & 15 & $75.0 \%$ \\
\hline Female & 5 & $25.0 \%$ \\
\hline $\begin{array}{l}\text { Cardiac } \\
\text { characteristics }\end{array}$ & 12 & \\
\hline $\begin{array}{l}\text { Acyanotic } \\
\text { disease }\end{array}$ & 8 & $60.0 \%$ \\
\hline cyanotic heart disease & 5 & $40.0 \%$ \\
\hline Without comorbidity & 15 & $25.0 \%$ \\
\hline With comorbidity & & $75.0 \%$ \\
\hline
\end{tabular}

section was the mode of delivery in all infants

b- History taking revealed that the majority of infants were full-term (17 infants, i.e., 85\%) and three infants $(15 \%)$ were preterm, and the majority (75\%) with average birth weight. The caesarian
$(100 \%)$. History of Neonatal Intensive Care Unit (NICU) admission was reported in $65 \%$ of the studied infants (mainly due to respiratory distress) table (2). 
Table (2): History taking findings

\begin{tabular}{|l|c|c|}
\hline & \multicolumn{2}{|c|}{$\begin{array}{c}\text { Total } \\
\text { (No=20) }\end{array}$} \\
\hline History of prematurity & No & $\%$ \\
\hline Full term & 17 & $85.0 \%$ \\
\hline Preterm & 3 & $15.0 \%$ \\
\hline Method of delivery & & $100.0 \%$ \\
\hline$\quad$ Caesarian section & 20 & $35.0 \%$ \\
\hline History of NICU admission & 7 & $65.0 \%$ \\
\hline$\quad$ No NICU admission & 13 & $75.0 \%$ \\
\hline$\quad$ NICU admission & & $25.0 \%$ \\
\hline Birth weight & 15 & \\
\hline Average & 5 & \\
\hline Below average & \multicolumn{2}{|c|}{} \\
\hline
\end{tabular}

$\mathrm{NICU}=$ Neonatal Intensive Care Unit.

c- Clinical feeding evaluation revealed:

Per oral safety was detected as a summary for clinical feeding and swallowing assessment. $40 \%$ of infants were judged clinically to be safe for oral feeding, and $60 \%$ were judged to be unsafe. Safety and unsafety judgment for oral feeding was decided clinically based on abnormal clinical findings such as cough and/or gurgly voice. Poor lip seal was

Table (3): Clinical feeding evaluation (CFE) findings demonstrated in $10 \%$ of infants, abnormal sucking was observed in $35 \%$ of infants. $90 \%$ of infants were bottle feeders, and $100 \%$ were on formula milk with prolonged duration of the meal in $45 \%$ of infants. The most common clinical finding was gagging during feeding in $85 \%$; cough during feeding in $65 \%$; a gurgly voice in $50 \%$ of infants, table (3).

\begin{tabular}{|l|c|c|}
\hline & \multicolumn{2}{|c|}{$\begin{array}{c}\text { Total } \\
\text { (No=20) }\end{array}$} \\
\hline CFE findings & No & \\
\hline Lip seal & & $90.0 \%$ \\
\hline Poor & 18 & $10.0 \%$ \\
\hline Good & 2 & $65 \%$ \\
\hline Sucking & 13 & $35 \%$ \\
\hline Normal & 7 & $45.0 \%$ \\
\hline Abnormal & & $55.0 \%$ \\
\hline Duration of the meal & 9 & $65.0 \%$ \\
\hline Prolonged & 11 & $35.0 \%$ \\
\hline Within average & 13 & $85.0 \%$ \\
\hline Cough & 7 & $15.0 \%$ \\
\hline Absent & & $50.0 \%$ \\
\hline Present & 17 & $50.0 \%$ \\
\hline Gagging & 3 & $60.0 \%$ \\
\hline Absent & & $40.0 \%$ \\
\hline Present & 10 & \\
\hline Gurgly voice & 10 & \\
\hline Absent & & \\
\hline Present & 12 & \\
\hline CFE summary & 8 & \\
\hline Unsafe & & \\
\hline Safe & & \\
\hline
\end{tabular}

$\mathrm{CFE}=$ Clinical Feeding Evaluation 
d- Videofluoroscopic swallowing study (VFSS) revealed that the most frequently observed VFSS findings were laryngotracheal aspiration and suck swallow breathing incoordination (SSBI). Laryngotracheal aspiration was detected in 15 infants (75\%); most of them (55\%) were silent aspirators. The laryngotracheal aspiration was due to SSBI. All infants who aspirated had separate swallows for which there was laryngeal penetration without aspiration, but laryngeal penetration was not detected without the occurrence of aspiration. SSBI was detected in 15 infants (75\%), where the typical ratio of $1: 1: 1$ was distorted. In all infants who demonstrated SSBI (i.e., 15 infants), delayed initiation of the pharyngeal swallow was detected as the liquid was seen deeper in the pharynx (to the pyriform sinuses) with multiple sucks per swallow.

The least frequently observed VFSS findings were pharyngeal residue and pharyngonasal backflow (PNB). Minimal residue in the pyriform sinuses was observed in 2 infants (10\%) and cleared with multiple swallows. PNB was noted in $30 \%$ of infants who were also silent aspirators due to associated SSBI. Per oral safety decision was based on the presence of aspiration in VFSS. Therefore, unsafe oral feeding was detected in $75 \%$ of the infants (table 4 ).

Table (4): Videofluoroscopic swallowing study (VFSS) findings

\begin{tabular}{|c|c|c|}
\hline & \multicolumn{2}{|c|}{$\begin{array}{c}\text { Total } \\
(\text { No=20) }\end{array}$} \\
\hline & No & No \\
\hline \multicolumn{3}{|l|}{ VFSS findings } \\
\hline \multicolumn{3}{|l|}{ Bolus formation } \\
\hline Normal & 14 & $70.0 \%$ \\
\hline Abnormal & 6 & $30.0 \%$ \\
\hline \multicolumn{3}{|l|}{ PPI } \\
\hline Normal & 5 & $25.0 \%$ \\
\hline Prolonged & 15 & $75.0 \%$ \\
\hline \multicolumn{3}{|l|}{ Pharyngeal nasal backflow } \\
\hline Absent & 14 & $70.0 \%$ \\
\hline Present & 6 & $30.0 \%$ \\
\hline \multicolumn{3}{|l|}{ SSBC } \\
\hline Uncoordinated & 15 & $75.0 \%$ \\
\hline Coordinated & 5 & $25.0 \%$ \\
\hline \multicolumn{3}{|l|}{ Aspiration } \\
\hline Absent & 5 & $25.0 \%$ \\
\hline present & 15 & $75.0 \%$ \\
\hline \multicolumn{3}{|l|}{ PAS scale } \\
\hline 1 & 5 & $25.0 \%$ \\
\hline 7 & 4 & $20.0 \%$ \\
\hline 8 & 11 & $55.0 \%$ \\
\hline \multicolumn{3}{|l|}{ Residue } \\
\hline Absent & 18 & $90.0 \%$ \\
\hline Present & 2 & $10.0 \%$ \\
\hline \multicolumn{3}{|l|}{ UES } \\
\hline No abnormality detected & 20 & $100.0 \%$ \\
\hline \multicolumn{3}{|l|}{ Summary of VFSS } \\
\hline Unsafe & 15 & $75.0 \%$ \\
\hline Safe & 5 & $25.0 \%$ \\
\hline
\end{tabular}

VFSS=Videofluroscopic Swallowing Study

SSBC $=$ Suck Swallow Breathing Coordination

PAS=Penetration Aspiration Scale

PPI=Pharyngeal Phase Initiation

UES=Upper Esophageal Sphincter 
e- Comparison between infants with comorbidities and infants without comorbidities revealed non-significant differences between both groups either in CFE findings

or in VFSS findings, table (5).

Table (5): Comparison between infants with and infants without comorbidities as regards their evaluation findings

\begin{tabular}{|c|c|c|c|c|c|c|}
\hline & \multicolumn{2}{|c|}{$\begin{array}{l}\text { CHD } \\
(n=5)\end{array}$} & \multicolumn{2}{|c|}{$\begin{array}{c}\text { CHD + } \\
\text { Cormorbidity } \\
(n=15)\end{array}$} & \multirow[t]{2}{*}{$\chi^{2}$} & \multirow[t]{2}{*}{$\mathbf{P}$} \\
\hline & No & $\%$ & No & $\%$ & & \\
\hline \multicolumn{7}{|l|}{ CFE findings } \\
\hline \multicolumn{7}{|l|}{ Lip seal } \\
\hline Poor & 5 & $100.0 \%$ & 13 & $86.7 \%$ & 0.741 & 0.389 \\
\hline Good & 0 & $0.0 \%$ & 2 & $13.3 \%$ & & \\
\hline \multicolumn{7}{|l|}{ Sucking } \\
\hline Normal & 3 & $60 \%$ & 10 & $66.7 \%$ & 0.073 & 0.787 \\
\hline Abnormal & 2 & $40 \%$ & 5 & $33.3 \%$ & & \\
\hline \multicolumn{7}{|l|}{ Duration of the meal } \\
\hline Prolonged & 3 & $60.0 \%$ & 6 & $40.0 \%$ & 0.606 & 0.436 \\
\hline Within average & 2 & $40.0 \%$ & 9 & $60.0 \%$ & & \\
\hline \multicolumn{7}{|l|}{ Cough } \\
\hline Absent & 3 & $60.0 \%$ & 10 & $66.7 \%$ & 0.073 & 0.787 \\
\hline Present & 2 & $40.0 \%$ & 5 & $33.3 \%$ & & \\
\hline \multicolumn{7}{|l|}{ Gagging } \\
\hline Absent & 5 & $100.0 \%$ & 12 & $80.0 \%$ & 1.176 & 0.278 \\
\hline Present & 0 & $0.0 \%$ & 3 & $20.0 \%$ & & \\
\hline \multicolumn{7}{|l|}{ Gurgly voice } \\
\hline Absent & 3 & $60.0 \%$ & 7 & $46.7 \%$ & 0.267 & 0.606 \\
\hline Present & 2 & $40.0 \%$ & 8 & $53.3 \%$ & & \\
\hline \multicolumn{7}{|l|}{ CFE summary } \\
\hline Unsafe & 3 & $60.0 \%$ & 9 & $60.0 \%$ & 0.000 & 1.000 \\
\hline Safe & 2 & $40.0 \%$ & 6 & $40.0 \%$ & & \\
\hline \multicolumn{7}{|l|}{ VFSS findings } \\
\hline \multicolumn{7}{|l|}{ Bolus formation } \\
\hline Normal & 4 & $80.0 \%$ & 10 & $66.7 \%$ & 0.317 & 0.573 \\
\hline Abnormal & 1 & $20.0 \%$ & 5 & $33.3 \%$ & & \\
\hline \multicolumn{7}{|l|}{ PPI } \\
\hline Normal & 0 & $0.0 \%$ & 5 & $33.3 \%$ & 2.222 & 0.136 \\
\hline Prolonged & 5 & $100.0 \%$ & 10 & $66.7 \%$ & & \\
\hline \multicolumn{7}{|l|}{ Pharyngeal nasal backflow } \\
\hline Absent & 5 & $100.0 \%$ & 9 & $60.0 \%$ & 2.857 & 0.091 \\
\hline Present & 0 & $0.0 \%$ & 6 & $40.0 \%$ & & \\
\hline \multicolumn{7}{|l|}{ SSBC } \\
\hline Uncoordinated & 5 & $100.0 \%$ & 10 & $66.7 \%$ & 2.222 & 0.136 \\
\hline Coordinated & 0 & $0.0 \%$ & 5 & $33.3 \%$ & & \\
\hline \multicolumn{7}{|l|}{ Aspiration } \\
\hline Absent & 0 & $0.0 \%$ & 5 & $33.3 \%$ & 2.222 & 0.136 \\
\hline present & 5 & $100.0 \%$ & 10 & $66.7 \%$ & & \\
\hline \multicolumn{7}{|l|}{ PAS scale } \\
\hline 1 & 0 & $0.0 \%$ & 5 & $33.3 \%$ & 3.030 & 0.220 \\
\hline 7 & 2 & $40.0 \%$ & 2 & $13.3 \%$ & & \\
\hline 8 & 3 & $60.0 \%$ & 8 & $53.3 \%$ & & \\
\hline \multicolumn{7}{|l|}{ Residue } \\
\hline Absent & 5 & $100.0 \%$ & 13 & $86.7 \%$ & 0.741 & 0.389 \\
\hline Present & 0 & $0.0 \%$ & 2 & $13.3 \%$ & & \\
\hline UES & & & & & & \\
\hline No abnormality detected & 5 & $100.0 \%$ & 15 & $100.0 \%$ & & \\
\hline Summary of VFSS & & & & & & \\
\hline Unsafe & 5 & $100.0 \%$ & 10 & $66.7 \%$ & 2.222 & 0.136 \\
\hline Safe & 0 & $0.0 \%$ & 5 & $33.3 \%$ & & \\
\hline
\end{tabular}

$\mathrm{CHD}=$ Congenital Heart Disease

CFE $=$ Clinical Feeding Evaluation

VFSS=Videofluroscopic Swallowing Study

SSBC $=$ Suck Swallow Breathing Coordination

$\mathrm{PAS}=$ Penetration Aspiration Scale

PPI=Pharyngeal Phase Initiation

UES=Upper Esophageal Sphincter

$\mathrm{X}^{2}=$ Chi-Square test

$\mathrm{P}$ is significant when $<0.05$ 


\section{Discussion:}

This study was conducted on 20 infants, 15 males $(75 \%)$ and 5 females $(25 \%)$ in the age range $2-19$ months (median seven months). As stated by Adil et al. (21) and Duncan et al. (22), infants and children under age 2 have the highest rate of oropharyngeal dysphagia than any other pediatric age group. Feeding assessment revealed that the two most frequent behaviors exhibited by the studied infants were gagging $(85 \%)$ and cough $(65 \%)$, followed by gurgly voice $(50 \%)$. The results are quite similar to the results of Weir et al.(23), who demonstrated that cough was the most frequently noted clinical marker in children with oropharyngeal dysphagia (46\%), followed by gurgly voice and breathing (41\%) and gagging (29\%). Additionally, In Pereira et al. (24) observed a low incidence of cough during swallowing. Only $25 \%$ of their studied CHD infants with oropharyngeal dysphagia showed cough during swallowing.

The most frequently observed VFSS findings in the current study were Laryngotracheal aspiration and SSBI. Laryngotracheal aspiration was detected in 15 infants (75\%); most of them $(55 \%)$ were silent aspirators. Similarly, laryngotracheal aspiration was the main VFSS finding in a number of studies on dysphagic infants younger than 1-2 years, including Silva et al. (25) and Duncan et al. (22), who observed laryngotracheal aspiration in 33\% and 38\% of their studied infants respectively. In agreement with the present study, these studies reported silent aspiration in more than $70 \%$ of their studied infants who demonstrated aspiration. The high prevalence of silent aspiration in infants is mostly due to the immaturity of neuromuscular systems and neurological comorbidity.

Our results corroborate the results of Sachdeva et al. (26) study that reported aspiration in 23 out of their studied 29 patients with congenital heart defects $(80 \%)$. In the latter study, laryngeal penetration occurred in five patients $(17 \%)$ and delayed triggering of swallowing in only one patient (3\%). Instrumental evaluation allowed researchers to identify oropharyngeal dysphagia in the population of children with congenital heart defects.

Yi et al. (27) performed a retrospective study to evaluate the prevalence and clinical predictors of dysphagia and determine the videofluoroscopic findings of swallowing in children with congenital heart diseases. Through videofluoroscopic findings, the authors concluded that $67.9 \%$ of the children had laryngeal penetration and $63.6 \%$ had tracheal aspiration, and of these, $85.7 \%$ of symptoms were silent, without cough. On the other hand, slightly lower aspiration rates were reported by Lee et al. (28), who detected laryngotracheal aspiration in $17.1 \%$ of their studied very low birth weight (VLBW) infants with oral feeding desaturation. The differences between studies are assumed to be due to differences in subject inclusion criteria, gestational age, and medical conditions.

In all our studied infants who demonstrated SSBI, laryngotracheal aspiration was detected. The results were in agreement with Pereira et al. (24), who demonstrated that oropharyngeal dysphagia in infants with CHD was mostly attributed to lack of coordination of the suck-swallow-breathe process, whether or not this was combined with stasis of food in the oral cavity, cough, anterior leakage, and fatigue during feeding. Additionally, Lau (29) stated that SSBI increased the risk of laryngotracheal aspiration in infants.

The current study revealed non-significant differences between infants with and infants without comorbidities regarding the occurrence of aspiration in 
VFSS (being the item of most interest).This finding indicates that oropharyngeal dysphagia in infants with CHD is related primarily to their cardiac illness, whether it was associated with another comorbidity or not.

\section{Conclusion}

Oropharyngeal dysphagia is a common clinical and videofluoroscopic finding in infants with congenital heart disease. The majority of the studied infants showed laryngotracheal aspiration caused by suckswallow-breathing incoordination. These findings point to the importance of the role of the phoniatricians in the early diagnosis and management of these infants to prevent the negative impact of dysphagia on the lives of these patients.

\section{References}

1. Teixeira FM, Coelho RM, Proença C, et al. Quality of life experienced by adolescents and young adults with congenital heart disease. Pediatr Cardiol 2011;32 (8):1132-1138

2. Van der Linde D, Konings EE, Slager MA, et al. Birth prevalence of congenital heart disease worldwide: a systematic review and meta-analysis. J Am Coll Cardiol 2011;58(21):2241-2247

3. Nousi D, Christou A (2010) Factors affecting the quality of life in children with congenital heart disease. Health Sci J 4:94-100

4. Lefton-Greif MA.(2008) Pediatric Dysphagia.Phys Med RehabilClin N Am. ;19(4): 837-51.

5. Gerdes M, Flynn T. Clinical assessment of neurobehavioral outcomes in infants and children with congenital heart disease Progress in Pediatr Cardiol 2010;29(2):97-105
6. Sables-Baus S, Kaufman J, Cook P, da Cruz EM. Oral feeding outcomes in neonates with congenital cardiac disease undergoing cardiac surgery. Cardiol Young 2012; 22(1):42-48

7. Weckmueller J, Easterling C, Arvedson J. Preliminary temporal measurement analysis of normal oropharyngeal swallowing in infants and young children. Dysphagia 2011;26(2):135-143

8. Silberstein D, Geva R, Feldman R, et al. The transition to oral feeding in low-risk premature infants: relation to infant neurobehavioral functioning and motherinfant feeding interaction. Early Hum Dev 2009;85(3):157-162

9. Jadcherla SR, Vijayapal AS, Leuthner S. Feeding abilities in neonates with congenital heart disease: a retrospective study. J Perinatol 2009;29(2):112-118

10. Woodward CS. Keeping children with congenital heart disease healthy. J Pediatr Health Care 2011;25(6):373-37

11. Swigert N. (1998): The source for pediatric dysphagia. East Moline, IL: Linguisystems

12. Homer, E. M. ,(2008).Establishing a public school dysphagia program: a model for administration and service provision.Language, Speech, and Hearing Services in Schools; 39: 177-191

13. Sharp W., Jaquess D., Morton J., and Herzinger C., (2010): Pediatric feeding disorders: A quantitative synthesis of treatment outcomes. Clinical child and family psychology review; 13(4):348-65 
14. Lefton-Greif M.A (2008): Pediatric dysphagia. Phys Med Rehabil Clin N Am; 19(4): 837-51.

15. Prasse J.E., and Kikano G.E., (2009): An overview of pediatric dysphagia. Clinical Pediatrics; 48(3): 247-251.

16. Rommel N., Dejaeger E., Bellon E., Smet M. and Veereman-Wauters G., (2006): Videomanometry reveals clinically relevant parameters of swallowing in children. Int J Pediatr Otorhinolaryngol; 70: 1397-1405.

17. Hiorns MP. and Ryan MM., (2006): Current practice in paediatric videofluoroscopy. Pediatr Radiol; 36(9): 911-915

18. Abou-Elsaad T. and Abdelatif G., (2008): Assessment of functional feeding and swallowing biomechanics in normal children. Banha Medical Journal; 25(3): 273-293

19. Newman L.A., Keckley C., Petersen M.C., et al., (2001): Swallowing function and medical diagnoses in infants suspected of dysphagia. Pediatrics 108: E106

20. Logemann, J. A. (1998). Evaluation and treatment of swallowing disorders. Austin, TX: PRO-ED.

21. Adil, E., Al Shemari, H., Kacprowicz A., Perez, J., Larson, K., Hernandez, K., et al.(2015): Evaluation and Management of Chronic Aspiration in Children With Normal Upper Airway Anatomy. JAMA otolaryngology-- head \& neck surgery; 141: $1006-11$

22. Duncan D.R., Mitchell P.D., Larson K. and Rosen R.L. (2018): Presenting signs and symptoms do not predict aspiration risk in children. J Pediatr; 201: 141-146.

23. Weir K., McMahon S., Barry L., Masters I.B., and Chang A.B., (2009): Clinical signs and symptoms of oropharyngeal aspiration and dysphagia in children . Eur Respir J.; 33 (3): 604-611

24. Pereira K., Firpo C., Gasparin M., Teixeira A., Dornelles S., Bacaltchuk T. and Levy D., (2015): Evaluation of Swallowing in Infants with Congenital Heart Defect, International Archives of Otorhinolaryngology.; 19: 55-60.

25. Silva M. L.F., Buhler K.E.B., and Limongi S.C.0., (2015): Comparison between clinical and videofluoroscopic evaluation of swallowing in children with suspected dysphagia. CoDAS 2015; 27(2): 186-92.

26. Sachdeva R, Hussain E,MossMM, et al. Vocal cord dysfunction and feeding difficulties after pediatric cardiovascular surgery. J Pediatr 2007;151(3):312-315, e1-e2

27. Yi SH, Kim SJ, Huh J, Jun TG, Cheon HJ, Kwon JY. Dysphagia in infants after open heart procedures. Am J Phys Med Rehabil 2013; 92(6):496-503

28. Lee J.H., Chang Y.S., Yoo H.S., Ahn S.Y., Seo H.J., Choi S.H., et al., (2011): Swallowing dysfunction in very low birth weight infants with oral feeding desaturation. World J Pediatr .; 7: 337-43.

29. Lau C., (2015): Development of suck and swallow mechanisms in infants, Ann Nutr Metab; 66(5): 7-14 